\title{
Crescimento da economia brasileira restrito pelo BP: um teste da lei de Thirlwall por técnicas de painel, 2000-2008
}

\author{
Augusta Pelinski Raiher* \\ Hermes Yukio Higachi* \\ Alex Sander Souza do Carmo ${ }^{* * *}$
}

RESUMO - O objetivo deste trabalho consiste em investigar se o crescimento brasileiro é consistente com o equilíbrio no setor externo. Para isso, estimou-se as elasticidades-renda das exportações e importações do país nos anos de 2000 a 2008, por meio de dados em painel. A partir dessas elasticidades foi possível estimar a taxa de crescimento prevista pela lei de Thirlwall, comparando-a, na sequência, com a taxa de crescimento econômico per capita efetiva do país.

Palavras-chave: Crescimento da economia brasileira. Lei de Thirlwall. Técnicas e dados em painel. Mudança estrutural.

\section{INTRODUÇÃO}

As teorias de crescimento econômico, em geral, buscam explicar quais são os fatores impulsionadores do crescimento econômico, ao mesmo tempo em que visam identificar porque os países crescem a taxas diferentes. Segundo Soares (2010), duas abordagens destacam-se neste debate: a neoclássica e a estruturalista (ou keynesiana). A grande diferença entre essas duas abordagens é que a primeira busca explicações por meio de fatores associados à oferta (capital físico, trabalho, capital humano) e a segunda via a demanda.

$\mathrm{Na}$ abordagem keynesiana, a questão a ser respondida se finda nos motivos pelos quais os países apresentam taxas de crescimento da demanda tão desiguais. Assim, ponderam que a demanda depende do consumo, do investimento e dos gastos governamentais, acrescendo na análise o setor externo. Considerando que as exportações são o único componente autônomo da demanda agregada, os teóricos ponderam a restrição no balanço de pagamentos como sendo o principal fator limitante do crescimento, em que somente por meio da expansão das exportações seria possível aumentar a taxa de crescimento da economia, sem deteriorar o balanço de

\footnotetext{
${ }^{*}$ Doutora em Economia pela Universidade Federal do Rio Grande do Sul. É professora adjunta do Departamento de Economia da Universidade Estadual de Ponta Grossa. Endereço eletrônico: apelinski@gmail.com.

** Doutor em Ciência Econômica pela Universidade Estadual de Campinas. É professor associado do Departamento de Economia da Universidade Estadual de Ponta Grossa. Endereço eletrônico: hhigachi@uepg.br.

*** Mestre em Desenvolvimento Econômico pela Universidade Federal do Paraná. É doutorando do Programa de Pós-Graduação em Desenvolvimento Econômico da Universidade Federal do Paraná. Endereço eletrônico: alexsscarmo@hotmail.com.
} 
pagamentos.

Thirlwall (1979) propõe que a explicação para as diferentes taxas de crescimento existentes entre os países origina-se nas restrições de demanda, que por sua vez vinculam-se ao equilíbrio no balanço de pagamentos. Para ele, a possibilidade de ampliar as exportações sem deteriorar a conta-corrente do balanço de pagamentos torna-se o elemento central, o qual impulsiona uma utilização mais adequada da capacidade produtiva instalada, a geração de novos investimentos, o desenvolvimento tecnológico e a continuidade do crescimento econômico. Neste sentido, o crescimento é liderado pelas exportações e o balanço de pagamentos pode limitar esse crescimento bem abaixo de seu potencial produtivo.

Com efeito, no modelo original de Thirlwall, a taxa de crescimento compatível com o equilíbrio externo é dada pela razão entre o coeficiente de elasticidade-renda da demanda por exportações e importações multiplicada pela taxa de crescimento da economia mundial. As exportações de produtos com níveis elevados de elasticidade-renda da demanda indicam produtos de maior valor adicionado, de origem industrial e de maior intensidade tecnológica, apresentado possibilidade de aumento da demanda frente à elevação da renda mundial. Além disso, os preços relativos tendem a ser favoráveis aos bens de maior valor adicionado, os quais, em geral, apresentam tendência de aumento tanto do consumo quanto de preços nos mercados internacionais.

Há uma extensa literatura que testa a validade empírica da lei de Thirlwall para o caso do crescimento da economia brasileira, porém, por meio de dados e técnicas de séries temporais. A partir dessas considerações, o objetivo deste trabalho é o de investigar se o crescimento brasileiro é consistente com o equilíbrio no setor externo, analisando o período de 2000 a 2008 , por meio de técnicas e dados em painel.

\section{ABORDAGEM ACERCA DO CRESCIMENTO ECONÔMICO: A LEI DE THIR- LWALL (LT)}

Partindo da hipótese de que as exportações são o único componente autônomo da demanda, mantendo, no longo prazo, constantes os termos de troca e, consequentemente, resultando num equilíbrio comercial, Thirlwall (1979) estimou a taxa de crescimento compatível com o equilíbrio do balanço de pagamentos (BP).

A formulação inicial especificada por Thirlwall (1979) baseou-se apenas na balança comercial como condição para o equilíbrio externo (GOUVÊA, 2010). Nela, a expansão da taxa de crescimento da economia é dada pela taxa de equilíbrio do BP, obtida da razão entre a taxa de crescimento das exportações (ou elasticidade-renda das exportações multiplicada pela 
taxa de crescimento da renda mundial) e a elasticidade-renda da demanda por importações. Isso significa que um país somente pode elevar sua taxa de crescimento com equilíbrio do BP se aumentar sua elasticidade-renda por exportações e/ou reduzir a elasticidade-renda das importações ao longo do tempo. Ou seja:

$$
\begin{aligned}
& X_{i}=\left(\frac{P_{d}}{E P_{f}}\right)^{\eta} Z^{\zeta} \\
& M_{i}=\left(\frac{E P_{f}}{P_{d}}\right)^{\psi} Y^{\varphi} \\
& P_{d} X_{i}=P_{f} M_{i} E
\end{aligned}
$$

Em que: $P_{d}$ e $P_{f}$ são os preços relativos do país e do resto do mundo, respectivamente. A taxa de câmbio entre as duas moedas é dada por E. $\psi$ é a elasticidade-preço da demanda por importação e $\eta$ é a elasticidade-preço da demanda por exportação. A renda doméstica e do resto do mundo são representadas por $Y$ e $Z$ e as elasticidades renda das exportações e importações são dadas por $\zeta$ e $\varphi$, respectivamente. O termo $i$ nas funções de demanda exportação/importação pode ser interpretado como setores, bens, países ou regiões de acordo com o escopo do estudo.

Fazendo o processo de log-linearização das funções de demanda por importação e exportação (representadas por letra minúscula) e calculando a variação ao longo do tempo, obtem-se (4), (5) e (6):

$$
\begin{aligned}
& m=\psi\left(p_{f}+e-p_{d}\right)+\varphi y \\
& x=\eta\left(p_{d}-e-p_{f}\right)+\zeta_{z} \\
& p_{d}+x=p_{f}+e+m
\end{aligned}
$$

Substituindo (4) e (5) em (6) e supondo que no longo prazo a variação nos termos de troca é negligenciável, chega-se em (7) e (7’):

$$
\begin{gathered}
\hat{y}=x_{i} / \varphi \\
\hat{y}=(\zeta / \Phi) z
\end{gathered}
$$


Assim, a taxa de crescimento do produto consistente com a satisfação da restrição relativa ao estabelecimento do equilíbrio externo é representada por (7) e (7’), a qual é conhecida como lei de Thirlwall (LT). Por meio da equação (7), verifica-se que quanto menor for a elasticidade-renda da demanda por importações ou quanto mais elevada for a taxa de crescimento das exportações maior será a taxa de crescimento de equilíbrio do balanço de pagamentos. Destacase que o aumento da renda mundial tem um efeito positivo sobre a taxa de crescimento do país, no entanto, é a razão da elasticidade-renda da demanda por exportações e importações que vai determinar a magnitude desse efeito, a qual capta o nível tecnológico e o padrão de especialização da estrutura produtiva de um país.

\section{ELEMENTOS METODOLÓGICOS}

Para avaliar a relevância da restrição externa no crescimento econômico brasileiro, utilizou-se a abordagem keynesiana do crescimento econômico sob restrição externa, formulada a partir da LT. Para isso, foram utilizadas informações acerca das importações e exportações de cada estado do Brasil no período de 2000 a 2008, oriundas do site Alice Web (valores em dólares, os quais foram deflacionados pelo Índice de Preço dos Estados Unidos). Além desses dados, usaram-se informações acerca do câmbio efetivo, PIB estadual e PIB mundial, obtidos junto ao site do IPEADATA, ressaltando que os dois últimos já se encontravam a preços constantes. Optou-se pelo período de 2000 a 2008 tendo em vista que a partir de 1999 o regime de câmbio adotado foi o flutuante. Segundo Pires de Souza e Hoff (2011), em janeiro de 1999, sob pressão de uma violenta crise cambial, o governo brasileiro adotou o regime de câmbio flutuante, para a qual ficou reservado o papel de promover o ajuste do balanço de pagamentos. De acordo com os autores, desde a implantação do regime de câmbio flutuante no Brasil, a economia logrou ajustes substanciais no balanço de pagamentos através de fortes desvalorizações cambiais, obtendo, ao mesmo tempo, expansão a taxas vigorosas do comércio internacional, não apenas superiores à do período de câmbio administrado, como também superiores à taxa de crescimento do comércio internacional. Assim, num novo regime cambial, buscou-se identificar a relevância da restrição externa no crescimento econômico brasileiro.

Inicialmente estimaram-se as elasticidades-renda das exportações do Brasil (8) e das importações (9). Como o objetivo era o de analisar a relevância da restrição externa no crescimento econômico brasileiro, fez-se uso da metodologia de dados em painel ${ }^{1}$, usando informações dos 26 estados do país mais o Distrito Federal, nos anos de 2000 a $2008^{2}$.

1 Optou-se por dados em painel tendo em vista que o número de anos analisados era pequeno para se usar a metodologia de série temporal.

2 Por meio do teste de Hausman decidiu-se pela estimação por efeito fixo. Destaca-se que todas as regressões 


$$
\begin{aligned}
& \ln X_{i t}=\varepsilon \ln z_{i t}+\eta \ln c a_{t}+C_{i}+u_{i t} \\
& \ln M_{i t}=\pi \ln y_{i t}+\varphi \ln c a_{t}+C_{i}+u_{i t}
\end{aligned}
$$

Em que: $i$ representa os estados, $t$ é o tempo; os parâmetros $\pi, \varphi$, ع e $\eta$ representam, respectivamente, a elasticidade-renda e preço das importações, e a elasticidade-renda e preço das exportações; $y$ é a renda interna; zé a renda mundial; ca é a taxa de cambio efetiva. $C$ é um componente não observável específico.

Por meio dessas elasticidades, estimou-se o crescimento econômico via a LT (7). Essa taxa foi comparada com a taxa de crescimento efetiva do período de 2000 a 2008, com dados oriundos do IPEADATA, compilados do World Development Indicators (WDI), valores estes medidos em dólares, no conceito de paridade do poder de compra (PPC). Para validar se o crescimento da economia brasileira no período de 2000-2008 foi restrito pelo balanço de pagamentos, usaram-se duas metodologias de validação: a prova t de student de contraste entre duas médias, e; a técnica de McGregor e Swales (1985), via estratégia do teste de regressão.

\section{CRESCIMENTO ECONÔMICO BRASILEIRO: APLICAÇÃO DA LEI DE THIR-}

\section{LWALL}

A abordagem keynesiana tem na restrição do balanço de pagamentos o principal fator limitante do crescimento econômico de um país. Mas especificadamente, a lei de Thirlwall propõe que diferentes taxas de crescimento existentes entre os países originam-se nas restrições de demanda, que por sua vez vinculam-se ao equilíbrio no BP.

GRÁFICO 1 - EVOLUÇÃO DA TAXA DE CRESCIMENTO DO PIB PER CAPITA BRASILEIRO (\%) E DO SALDO DO BP (EM TRILHÕES DE DÓLARES) - 1981 A 2008

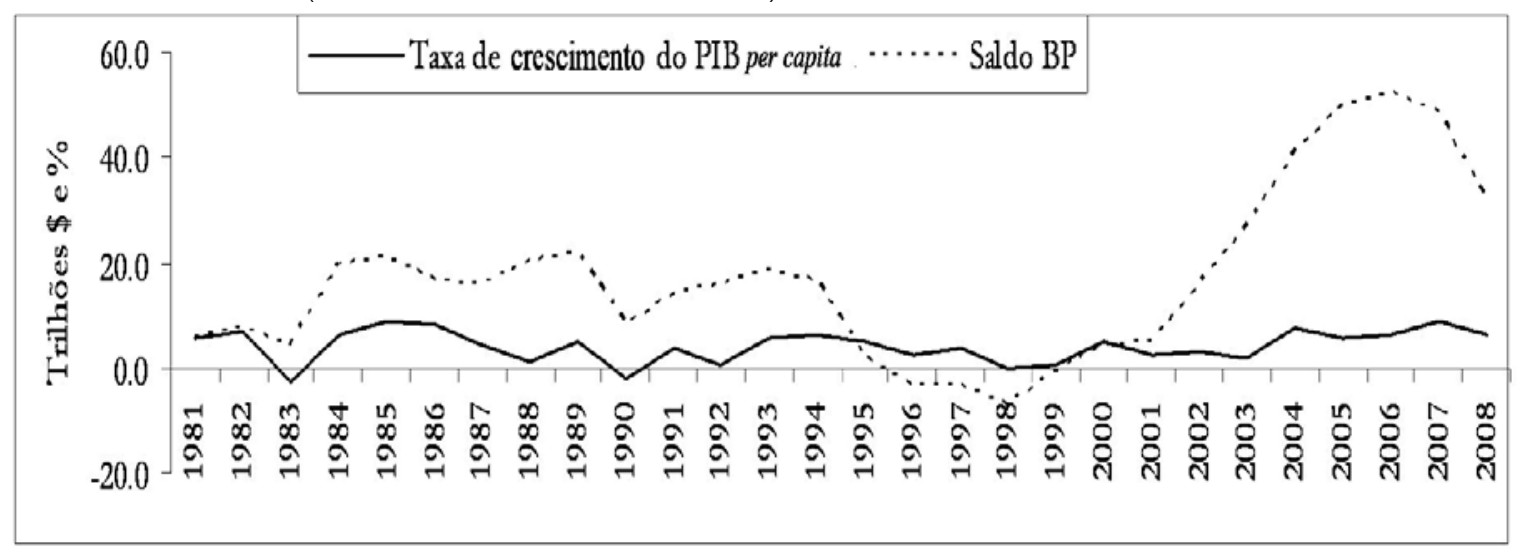

FONTE: Resultado da pesquisa.

foram efetuadas no software Stata. 
Se analisarmos a evolução da taxa de crescimento do PIB per capita do Brasil nas últimas três décadas (Gráfico 1), verificaremos que este teve um crescimento médio igual a 4,98\%, 2,37\% e 5,10\%, correspondendo a década de 1980, 1990 e 2000, respectivamente. Se compararmos esse crescimento com a evolução do saldo da balança comercial do país (Gráfico 1) observar-se-á uma forte ligação entre o desempenho econômico do país com a sua vulnerabilidade externa ${ }^{3}$, principalmente quando se analisa a partir da segunda metade dos anos de 1990.

Partindo desta constatação, e considerando que a lei de Thirlwall produz uma taxa de crescimento do produto consistente com a satisfação da restrição relativa ao estabelecimento do equilíbrio externo, será então que a estimação do crescimento via LT é condizente com o crescimento efetivo do Brasil, considerando os anos de 2000? Ou seja, será que o crescimento do Brasil é restrito pelo seu balanço de pagamentos?

Para estimar o crescimento do PIB per capita por meio da LT é necessário identificar, $a$ priori, as elasticidades-renda das exportações e importações do Brasil, as quais são apresentadas na Tabela 1. No caso das exportações, apenas a demanda internacional a influencia, ao passo que, para as importações tanto o dinamismo econômico interno como também a taxa de câmbio são fatores decisivos na sua determinação.

TABELA 1 - ELASTICIDADE-RENDA E ELASTICIDADE-PREÇO DAS EXPORTAÇÕES E IMPORTAÇÕES BRASILEIRA - 2000 A 2008

\begin{tabular}{lrr}
\hline Variável dependente & Elasticidade-renda & Elasticidade-preço \\
\hline Exportação & 3,44 & 0,52 \\
& $(3,05)^{*}$ & $(0,72)$ \\
Importação & 1,25 & $-1,15$ \\
& $(9,56)^{*}$ & $(5,56)^{*}$ \\
\hline
\end{tabular}

FONTE: Resultado da pesquisa.

NOTA: Estatística t-student entre parênteses; * significativo a $1 \%$.

Assim, com essas elasticidades pode-se estimar a taxa de crescimento do PIB per capita do país via LT (7). Nos anos de 2000 a 2008, o crescimento médio do PIB per capita do Brasil foi igual a 5,10\% a.a., enquanto que a taxa de crescimento estimada correspondeu a 5,86\% a.a. (Tabela 2), valor bastante próximo do crescimento efetivo, com um erro de previsão do modelo de apenas $0,76 \%$.

A validação da estimativa da LT é também apresentada na Tabela 2, na qual se comparou a taxa de crescimento prevista pelo modelo e a taxa de crescimento do PIB per capita efetivo, por meio da prova t de student de contraste entre duas médias. Como o valor do teste t de student encontrado $(-0,86)$ foi menor que o seu valor crítico $(1,89)$, com n-1 graus de liberdade e nível de significância de $5 \%$, então não se pode rejeitar a hipótese de que a taxa de crescimento do 3 Cujo coeficiente de correlação obtido entre essas duas variáveis foi positivo e significativo a um nível de significância de $1 \%$ (coeficiente igual a 0,558 ). 
PIB per capita, compatível com o crescimento externo, não é distinta à taxa efetiva do período.

Além da prova t de student, submeteu-se o resultado a um teste mais formal de validação, aplicando-se a metodologia de McGregor e Swales (1985), via estratégia do teste de regressão, visando identificar se a taxa de crescimento do PIB per capita estimada pela LT é distinta da taxa de crescimento do PIB per capita efetivo. Regrediu-se a taxa de crescimento do PIB per capita efetivo contra a taxa de crescimento estimada, verificando-se, na sequência, se é possível rejeitar a hipótese nula de que a declividade e o intercepto da reta de regressão são iguais a 1 e a 0 , respectivamente. Os resultados apresentados na Tabela 3 corroboram com os encontrados na Tabela 2, os quais sugerem a validade do modelo, uma vez que, pelo teste F de restrições conjuntas, não é possível rejeitar a hipótese nula, validando o modelo.

TABELA 2 - TAXAS DE CRESCIMENTO DO PIB PER CAPITA: LEI DE THIRLWALL (LT) E EFETIVA - 2000 A 2008

\begin{tabular}{l|r}
\hline & Crescimento médio do PIB per capita $\mathbf{2 0 0 0 - 2 0 0 8 ~ ( \% )}$ \\
\hline Efetivo & 5,10 \\
LT & 5,86 \\
Erro & $-0,76$ \\
Estatística t-student & $-0,86$ \\
\hline
\end{tabular}

FONTE: Resultado da pesquisa.

TABELA 3 - TESTE DAS REGRESSÕES DE VALIDADE DA LT: BRASIL - 2000 A 2008

\begin{tabular}{lr}
\hline \multicolumn{1}{c|}{ Variável Independente } & Crescimento PIB per capita \\
\hline LT & 0.55 \\
& $(2.77)^{*}$ \\
Constante & 0.011 \\
R2 & $(0.71)$ \\
Teste de regressão: inclinação igual a 1 e intercepto zero & 0.56 \\
\hline
\end{tabular}

FONTE: Resultado da pesquisa.

NOTA: Estatística t-student entre parênteses; * significativo à 5\%; + p-valor da estatística F.

Desta forma, empiricamente validou-se a hipótese de que a restrição do balanço de pagamentos tem determinado o crescimento da economia brasileira. Como essa restrição depende sobremaneira das elasticidades-renda das exportações e das importações, a investigação acerca da composição dessas exportações/importações do país torna-se relevante para que concepções de iniciativas de políticas industriais, visando o alivio estrutural da restrição externa ao crescimento sustentado, venham a ser tomadas. Assim, no Gráfico 2 é apresentada a participação das indústrias, distribuídas por níveis tecnológicos, e a participação dos outros produtos não industriais nas exportações do país. Em 2000, a indústria de baixa tecnologia tinha a maior participação nas exportações do país, seguida da média-baixa, da média-alta, dos produtos não industriais e da alta tecnologia. Em 2008, a indústria de média-baixa intensidade tecnológica tem o maior peso nas exportações, seguida das de baixa tecnologia, dos produtos não indus- 
triais (que são basicamente os produtos da agropecuária), da média-alta e, por último, da alta tecnologia. Além de terem as menores contribuições, a alta tecnologia e a indústria de médiaalta tiveram perdas de participação se comparado com suas contribuição de 2000 para 2008.

Isso significa que o padrão de especialização das exportações do país está ancorado basicamente em produtos de média-baixa e baixa intensidade tecnológica, explorando vantagens comparativas do país por meio do uso de recursos naturais e mão de obra de baixo custo. Ao mesmo tempo, os setores que compõem a indústria intensiva em tecnologia vêm perdendo espaço. Como as exportações dessas indústrias apresentam maiores elasticidades-renda da demanda e um maior potencial de aprendizado tecnológico e de geração de externalidades tecnológicas positivas nos demais setores econômicos (DOSI; PAVITT' SOETE, 1990; GÔUVEIA, 2010), a sua diminuição na participação das exportações limita qualquer expectativa de crescimento econômico mais intenso do país nos anos seguintes.

GRÁFICO 2 - PARTICIPAÇÃO DOS SETORES INDUSTRIAIS POR INTENSIDADE TECNOLÓGICA E DE OUTROS PRODUTOS NÃO INDUSTRIAIS NAS EXPORTAÇÕES DO BRASIL - 2000 A 2008 (\%)

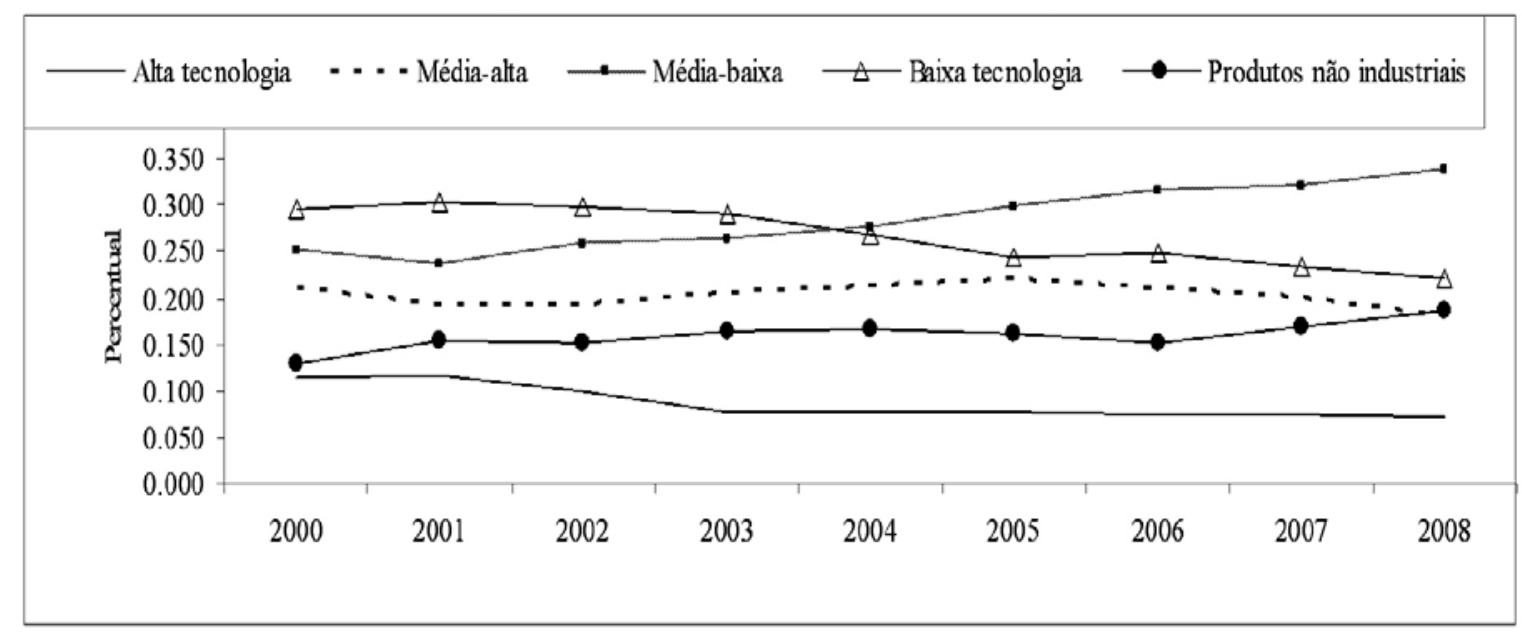

FONTE: Dados originais do Alice Web, trabalhado pela pesquisa.

\section{CONSIDERAÇÕES FINAIS}

O crescimento da economia brasileira foi restrito pelo balanço de pagamentos no período 2000-2008: a demanda externa e a estrutura produtiva captada pela razão das elasticidades-renda da demanda por exportações e importações são os determinantes do crescimento de médio e longo prazo da economia brasileira.

Por sua vez, o padrão de especialização das exportações da economia brasileira busca explorar a abundância de recursos naturais e de mão de obra de baixo custo. Portanto, uma mudança na estrutura de produção e na exportação para bens de alta e média-alta tecnologia, poderá contribuir para elevar o potencial de crescimento de médio e longo prazo da economia 
brasileira.

\section{REFERÊNCIAS}

CARVALHO, V. R.; LIMA, G. T. Macrodinâmica do produto e da renda sob restrição externa: a experiência brasileira no período 1930-2004. Economia Aplicada, v. 12, n. 1, p. 55-77, 2008.

DOSI, G.; PAVITT, K.; SOETE, L. The economics of technical change and international trade. Brighton: Harvester Whestsheaf, 1990.

GOUVÊA, R. R. Padrão de especialização produtiva e crescimento econômico sob restrição externa: uma análise empírica. 168 f. Dissertação (Mestrado em Economia) - Faculdade de Economia, Administração e Contabilidade da Universidade de São Paulo, São Paulo, 2010.

MCGREGOR, P. G.; SWALES, J. K. Professor Thirlwall and balance-of-payments-constrained growth. Applied Economics, v. 17, p. 17-31, 1985.

THIRLWALL, A. The balance of payments constraint as an explanation of international growth rates differences. Banca Nazionale del Lavoro Quarterly Review, v. 128, 1979. 
